\title{
SMall Autonomous AircRaft For ECONOMICAL OCEANOGRAPHIC OBSERVATIONS ON A WIDE SCALE
}

Tad McGeer and Greg J. Holland

\begin{abstract}
A PRototype AEROSONDE, which will fit comfortably on a desktop, and can be packed in two boxes sufficiently small to be taken as airline luggage, is shown in Figure 1. It will have a range of over $7,000 \mathrm{~km}$, endurance up to 4 days, capacity for precision navigation anywhere on the globe and for timely communication back to your desktop $\mathrm{PC}$, and full autonomy, so that it will not require continuous monitoring during flight. Its payload will be sufficient for a variety of lightweight oceanographic and atmospheric sensors, including radiosonde-type meteorological instruments, a short-range radar altimeter, solar/infrared (IR) and broad-band radiometers combined with a precise attitude reference, an optical rain gauge, or a video camera with a short-range downlink. Aerosondes may be operated on long autonomous missions or over short distances from a controlling ship or coastal station, in quantity for operational reconnaissance and major field programs, or individually, perhaps even by the solo researcher with little more than a laptop, a modem, and a small field for launch and recovery. If used in large numbers their unit cost should be on the order of $\$ 10.000$.

The initial stimulus for developing aerosondes has come from meteorology. Lack of comprehensive atmospheric soundings in remote areas has been a chronic problem for decades, and the consequences have become increasingly apparent as numerical models have improved. Sparsity of observational data, rather than model fidelity, is now more commonly the limiting factor in forecast accuracy (ICSU, 1992). Consequently there is a pressing need for new reconnaissance techniques, which must be sufficiently flexible to fill very large data voids in oceanic and remote areas, and also sufficiently economical for routine deployment on a wide scale. It is testimony to the aerosonde's ability to satisfy these requirements that the World
\end{abstract}

T. McGeer, The Insitu Group, 224 Robin Way, Menlo Park, CA 94025. USA. G.J. Holland. Bureau of Meteorology Research Centre, GPO Box 1289K, Melbourne, Victoria 3001, Australia.
Meteorological Organisation (WMO) and International Council of Scientific Unions (ICSU) have placed high priority on its development for reconnaissance of tropical cyclones (ICSU, 1992, 1993).

Our purpose here is to outline planned and potential roles for the aerosonde over ocean regions and to alert a general oceanographic audience to the technical opportunity at hand. We will first discuss performance, then economics, and finally some example applications.

\section{Technical Description}

Aerosondes are analogous to personal computers in that they combine high performance with the benefits of small size: low cost of manufacture and use, easy shipment, assembly and operation by a single person, opportunistic basing, and independence from elaborate facilities. Just as this combination of features has made computing much more accessible than was possible with mainframes alone, so aerosondes promise to make long-range observational programs considerably easier than is now possible with large aircraft and ships. Their development, like that of small computers, is made possible by miniaturization of the necessary electronics- and in particular by the equipment listed in Table 1, which lists all electronics and related components necessary for long-range autonomous flight. Prominent on the list are the Inmarsat $C$ and the global positioning receiver (GPS); the former provides two-way geosynchronous relay everywhere except at high latitudes, and the latter allows precise navigation worldwide. It is their emergence into common use over the last 2 years that has made aerosondes feasible. Moreover by the mid- to late 1990s substantial improvements will become possible. By then several low-earth-orbiting satellite networks will be competing for global voice and data services (AIAA, 1992; Ware, 1992), which by comparison with Inmarsat will decrease component weights and power requirements by one order of magnitude (and costs as well).

The weights of all the components in Table 1 sum to only $4 \mathrm{~kg}$ or so, and their power requirement
Aerosondes are

analogous to

personal computers

. . . they combine

high performance

with the benefits of

small size . . . 


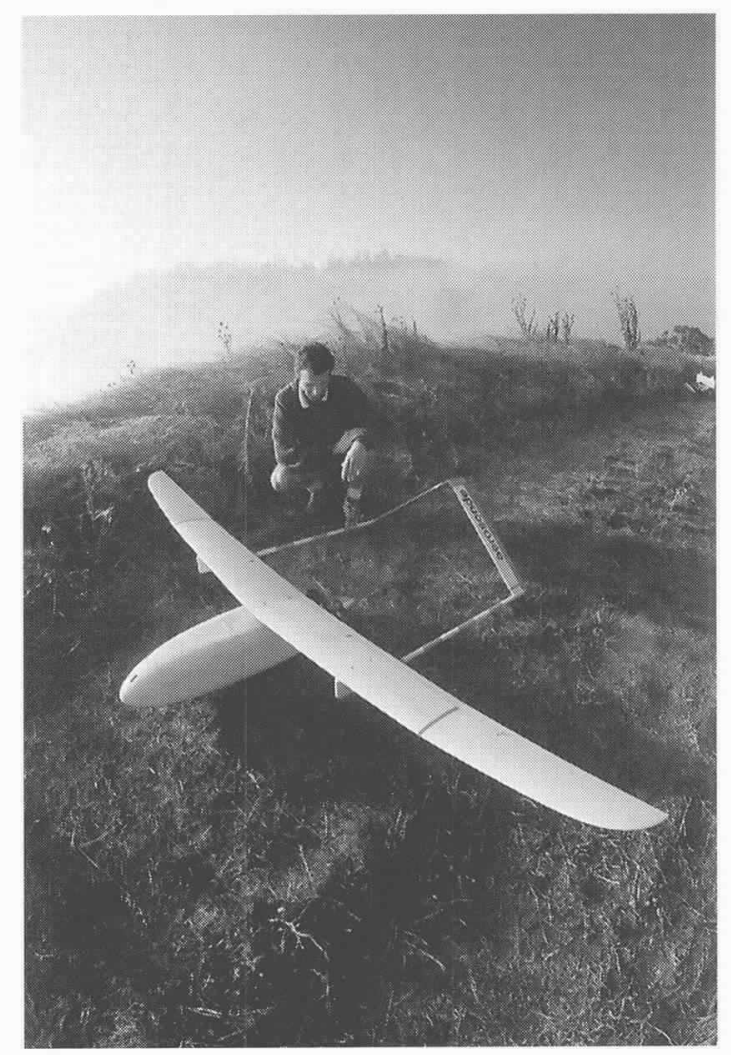

Fig. 1: The second aerosonde prototype, which was used for avionics development and demonstrated GPS-guided autonomous flight in mid-1993. It has since been succeeded by the third prototype, with a new engine and fuel sufficient for about 4,000 km range. Operational aircraft will follow directly and will have the same general arrangement.

amounts to only a few watts. Given these figures, even very small aircraft become capable of extraordinary missions. Of course their size depends upon the desired range and other performance objectives, and upon the weights of additional items to be carried. For meteorological reconnaissance nothing more is needed because pressure, temperature, humidity, and wind components can be determined from "engineering" sensors, i.e., those that would be carried in any case for guidance and control. Hence a meteorological sounder is sized for range, and the aircraft specified in Table 2 represents a reasonable compromise between limiting size on the one hand and flying long missions on the other. This aircraft could remain airborne for 2 days and fly comfortably from, say, Newfoundland to Ireland. When Inmarsat $C$ is replaced by a low-earth-orbit relay it will be possible to extend missions to 4 days, and so fly from, say, Japan to Hawaii. Notice that the airspeed is low, which turns out to be obligatory when long range is sought from a small aircraft (McGeer, 1991). This means that range could be extended substantially by a tailwind, but it also means that routes must be planned to avoid strong headwinds.
It is important to emphasize that no untried technology is necessary to achieve performance at this level. Feasibility can be demonstrated by reference to the classical Breguet equation for range:

$$
\mathrm{R}=\frac{\eta_{p}}{\mathrm{c}} \frac{\mathrm{L}}{\mathrm{D}} \ln \frac{\mathrm{W}_{\mathrm{t} / 0}}{\mathrm{~W}_{\text {end }}}
$$

The elementary derivation of this formula is given, for example, by McCormick (1979); it calculates the distance required to dissipate deliverable fuel energy into aircraft drag. Terms are as follows:

1. $\eta_{\mathrm{p}}$, the propellor efficiency, is $\sim 0.7$ for the off-the-shelf model propellor flying on our current prototype and can be increased beyond 0.8 with some care in design (McGeer, 1991).

2. L/D, the airframe lift-to-drag ratio, is $\sim 20$ when flying around $20 \mathrm{~m} / \mathrm{s}$. This is calculated in McGeer (1991), and (like the propellor efficiency) follows from fundamental aerodynamic considerations. It is only weakly dependent on altitude, so range hardly varies as altitude is changed (although the time required to cover the range certainly does). Range is similarly unaffected by repeated climbs and descents, as in a sounding cycle. However at a small scale, aerodynamic efficiency must be guarded with some care. For example, an instrumentation probe that might hardly be noticed on a larger aircraft must be properly streamlined on an aerosonde.

3. c, the specific fuel consumption, is $\sim 4.5$ $\mathrm{N} / \mathrm{kWh}$ (i.e., $1 / \mathrm{c}=800 \mathrm{~km}$ ) for our prototype engine, which is a modified version of a standard engine used by aircraft modelers. This figure is not particularly good by large-engine standards and certainly can be improved with development. However, as it stands, it will allow quite adequate performance.

4. $\mathrm{W}_{\mathrm{t} / 0} / \mathrm{W}_{\text {end }}$ is the ratio of gross weight to empty weight and so depends on how much of the gross weight is taken up by structure and fixed equipment. This ratio will be $\sim 1.5$ for initial aircraft and 1.8 when lighter avionics leave room for more gasoline. There is nothing exotic about the associated structural design, although its small scale means that it can be very robust. In fact an aircraft of this size does not require an undercarriage; the fuselage is strong enough for landing on any reasonably smooth surface. (Takeoff can be done from a dolly, cartop, or catapult.) Similarly the airframe will survive even severe turbulence.

Thus aerosonde development is a problem of integrating existing technologies, and consequently the range and endurance of the end product can be anticipated with high confidence. However the effort required to create this end product is substantial, and the prudent approach is to proceed through a series of design iterations and field trials. Our initial trials aircraft (Table 2) is planned as a modest 
Table 1

Avionics and related equipment required for long-range autonomous flight

\begin{tabular}{|c|c|c|c|c|c|c|}
\hline & \multicolumn{3}{|c|}{1994} & \multicolumn{3}{|c|}{1996} \\
\hline & $\begin{array}{l}\text { Weight, } \\
\text { gm }\end{array}$ & $\begin{array}{c}\text { Power, } \\
\text { W }\end{array}$ & $\begin{array}{l}\text { Cost, } \\
\text { US\$ }\end{array}$ & $\begin{array}{l}\text { Weight, } \\
\text { gm }\end{array}$ & $\begin{array}{c}\text { Power, } \\
\text { W }\end{array}$ & $\begin{array}{l}\text { Cost, } \\
\text { US\$ }\end{array}$ \\
\hline Onboard computer & 70 & 0.39 & 2.000 & 70 & 0.39 & 500 \\
\hline Data acquisition board & 170 & 1.00 & 1,000 & 70 & 1.00 & 200 \\
\hline Combined Inmarsat C/GPS & 2,500 & 12.00 & 5,000 & & & \\
\hline Combined LEO relay/GPS & & & & 320 & 3.00 & 700 \\
\hline Short-range data link, incl. antenna & 220 & 1.40 & 500 & 220 & 1.40 & 500 \\
\hline Pitot transducer & 5 & & 80 & 5 & & 80 \\
\hline Yaw rate gyro & 50 & 0.12 & 300 & 50 & 0.12 & 300 \\
\hline Heading sensor & 70 & 0.32 & 500 & 200 & 1.00 & 500 \\
\hline Echo altimeter & & & & 100 & 0.50 & 100 \\
\hline Tachometer & 5 & & 5 & 5 & & 5 \\
\hline Exhaust-gas sensor & 10 & & 30 & 10 & & 30 \\
\hline $2 \times \mathrm{P}, \mathrm{T}, \mathrm{H}$ sensors & 110 & 0.10 & 100 & 200 & 0.10 & 100 \\
\hline Packaging, mounting, and wiring & 450 & & 100 & 200 & & 100 \\
\hline Control servoes & 280 & 1.60 & 240 & 315 & 1.80 & 270 \\
\hline Total avionics & 3,940 & 17 & 9,855 & 1,765 & 9 & 3,385 \\
\hline Generator incl. mount and drive & 150 & & 5 & 150 & & 5 \\
\hline Battery pack & 250 & & 5 & 250 & & 5 \\
\hline Power conditioning & & & & 100 & & 100 \\
\hline OVERALL TOTAL & 4,340 & & 9,865 & 2,265 & & 3,495 \\
\hline
\end{tabular}

step in design from the current prototypes, to be fielded (under benign conditions) in 1995. Then as experience accumulates we will move toward more refined design and operating techniques which, together with lighter avionics, should increase range and endurance roughly twofold by 1997 . A further step will be toward higher ceiling, which is of great interest for many meteorological applications. This will require a supercharged engine and a number of associated components (McGeer, 1991), all of which call for novel design to an unusual set of requirements (small displacement, high pressure ratio, light weight, and high efficiency). The novelty at this later stage precludes firm specification of ultimate ceiling, but we regard $100 \mathrm{hPa}(\sim 16 \mathrm{~km})$ as a reasonable expectation.
. . as experience

accumulates we

will move toward

more refined design

and operating

techniques...

Table 2

Projected aerosonde specifications

\begin{tabular}{|c|c|c|}
\hline & 1995 & $\sim 1988$ \\
\hline \multicolumn{3}{|l|}{ Dimensions } \\
\hline Wing span, m & 2.9 & 3.0 \\
\hline Wing area, $\mathrm{m}^{2}$ & 0.55 & 0.55 \\
\hline Propellor diameter, m & 0.60 & 0.85 \\
\hline \multicolumn{3}{|l|}{ Weights, kg } \\
\hline Avionics & 4.3 & 2.4 \\
\hline Powerplant & 1.5 & 3.2 \\
\hline Airframe & 3.6 & 2.0 \\
\hline Gasoline & 4.5 & 6.1 \\
\hline Oil & 0.1 & 0.3 \\
\hline Gross & 14 & 14 \\
\hline \multicolumn{3}{|l|}{ Performance } \\
\hline Propellor efficiency & 0.7 & 0.8 \\
\hline Optimum L/D at SL & 18.5 at $21 \mathrm{~m} / \mathrm{s}$ & 20 at $20 \mathrm{~m} / \mathrm{s}$ \\
\hline Maximum speed & $38 \mathrm{~m} / \mathrm{s}$ at $\mathrm{SL}$ & $70 \mathrm{~m} / \mathrm{s}$ at $16 \mathrm{~km}$ \\
\hline Range to zero fuel at econ. cruise, $\mathrm{km}$ & 3,700 & 7,500 \\
\hline Range to zero fuel at max. speed, $\mathrm{km}$ & 2,800 & 5,800 \\
\hline SL climb rate, $\mathrm{m} / \mathrm{s}$ & 2.9 & 3.4 \\
\hline Service ceiling. $\mathrm{km}$ & 5 & 16 \\
\hline Time to ceiling at gross weight, $\mathrm{hr}$ & 0.8 & 1.3 \\
\hline Climb/descent cycle time, $\mathrm{hr}$ & 1.9 & 4 \\
\hline Endurance in climb/descent cycle, days & 2 & 2.8 \\
\hline Endurance at sea level, days & 2.3 & 4 \\
\hline
\end{tabular}

An initial version should be ready for field trials in 1995 , and refined models will follow over several years of development. 
As mentioned above, many applications will require equipment other than that listed in Table 1. Such equipment could be accommodated by displacing fuel, with a consequent loss of range which can be calculated from the Breguet equation. With an additional $3 \mathrm{~kg}$ of instruments, for example, the "initial trails" aerosonde would have $\sim 1,000-\mathrm{km}$ range and endurance of $\sim 12$ hours. If more range were required then a somewhat larger aircraft could be built, at a cost that should be modest once a standard component set is in place.

\section{Prospective Economics}

It is important to think of aerosondes as consumables rather than as items of capital equipment. In our view it will not be at all unusual for aircraft on long-range missions to be lost to adverse weather (mainly icing) even with due care in flight planning. Some will also be lost to equipment failure, but we believe that this rate can be kept comparatively small. That is why our design philosophy is rigorously minimalist: while on a manned aircraft it would be obligatory to have twin engines, dual generators, and so forth; on an aerosonde the more economical approach is to pare the equipment list. This makes the aircraft as small and cheap as possible, which both minimizes the cost of inevitable losses and confers economies attendant upon small scale.

We reckon the economics as follows. Ten percent overall attrition seems a reasonable expectation, which corresponds to an average lifetime approaching 1,000 flight hours. Preliminary discussions among meteorological services, including representatives of WMO and ICSU, the NOAA Forecast Systems Laboratory, and the Australian Bureau of Meteorology, suggest that at this rate $\sim 1,000$ aircraft per year could be used for operational weather reconnaissance. (This number would be sufficient to supply $\sim 30 \%$ of the sounding data now generated by the global network of balloon-borne rawinsondes.) Unit price at this production rate would be on the order of $\$ 10,000$. For lower levels of production, say 50 aircraft per year for research only, unit price would be severalfold higher. Larger aircraft designed to carry special research payloads would cost more as well, perhaps on the order of $\$ 100,000$ if bought in dozens. Amortization of these first costs at our expected attrition rate would range from $\sim \$ 10$ to $\sim \$ 100$ per flight-hour.

Running costs must be added, including those for ground staff, facilities, maintenance, repair, and communications. For routine reconnaissance work, in which several aircraft might rotate continuously through a fixed base, these would amount to a few tens of dollars per flight-hour. However many oceanographic applications will be associated with research projects, and corresponding costs will vary from one program to the next-and indeed may be hard to separate from those for other field activities. As a general state- ment we can say that we see a good prospect of total operating costs below $\$ 100$ per flight hour.

\section{Regulatory Issues}

The aerosonde is one of several autonomous aircraft being proposed for civil use (Goo et al., 1989; Albritton et al., 1990; Langford and Emmanuel, 1990). These proposals represent a new frontier, since autonomous-aircraft operations previously have been exclusively military and even then rather limited in scope. Obvious issues of air traffic control and collision hazard therefore are being faced for the first time. Birds and even radiosondes already present a collision risk much greater than that associated with plausible numbers of autonomous aircraft (McGeer, 1991), but nevertheless this new hazard must be controlled by both technical and regulatory measures.

The definitive technical solution will be active collision avoidance independent of ground control. One method would be for the autonomous aircraft to interrogate "mode C" transponders of other aircraft in its vicinity, and so determine their altitudes and approximate ranges. The onboard computer then could select a clear altitude if a conflict were indicated. An even better option for the longer term would be a mutual alerting system based on local broadcasting of GPS position. Such a system has been demonstrated by aeronautics authorities in Sweden (Nilsson, 1992), but although it is very attractive technically we cannot expect widespread adoption before the next century.

The practical solution for the present is to avoid busy airspace. Oceanographic applications present little difficulty on this point. Low-altitude traffic over oceans is essentially nil, whereas highaltitude traffic operates under instrument flight rules on well-defined routes that an aerosonde could avoid reliably. Appropriate flight planning will not be unduly complicated or restrictive. Operations near coastal bases are likely to be more constrained, but even there low-altitude activity is light, and special dispensation can be obtained. For airspace under U.S. jurisdiction the FAA intends to be flexible and handle such arrangements case by case until there is sufficient experience to develop a more general policy.

\section{Some Applications}

The aerosonde's applications in meteorology include extension of the global upper-air (i.e., balloon sonde) network over oceanic and remote areas, reconnaissance of tropical cyclones including both eye sounding and near-environment surveillance; reconnaissance of other severe weather conditions; intensive soundings for research; and ongoing ground-truth surveys to maintain satellite calibration (Holland et al., 1992). These applications involve measurement of pressure, temperature, humidity, and wind with accuracies specified 
by WMO ( $\pm 1 \mathrm{hPa}, \pm 0.5^{\circ} \mathrm{C}, \pm 5 \%$ (to $300 \mathrm{hPa}$ ), and $\pm 1 \mathrm{~m} / \mathrm{s}$, respectively); we expect that these requirements can be met comfortably with paired radiosonde-type sensors and GPS-based calculations for wind. Here we mention a few additional possibilities in oceanography. Others will probably be recognized as field experience accumulates.

\section{Targeted Monitoring of Remote Areas}

In field experiments over oceanic regimes, the selection of monitoring sites is often dictated as much by logistics as by scientific preference. Aerosondes offer new flexibility. In combination with convenient fixed sites, ships, and satellites, they can provide comprehensive coverage of almost any region of interest.

An example is the aerosonde deployment planned during the Maritime Continent Thunderstorm Experiment (MCTEX), which will be conducted on and around Bathurst and Melville Islands off northern Australia in 1995-1996 (Fig. 2) (BMRC, 1992). The islands generate a severe convective complex (known locally as Hector) in a daily cycle during the monsoon transition seasons (Keenan et al., 1989a,b). The cycle is typical of those over the "maritime continent" area of Indonesia and the Philippines, which is distinguished by its unique mixture of warm water and diurnally heated islands. MCTEX will examine the diurnal cycle in detail, together with the oceanic and island changes that occur as the summer wet season progresses.

The results are needed for understanding interactions between convective elements and their impact on the larger-scale environment, with applications including sub-grid parameterization in climate models. The MCTEX program also provides a testbed for the ambitious Atmospheric Radiation Measurement program of the U.S. Department of Energy, whose plan includes extended monitoring over a large oceanic region in the western equatorial Pacific.

Aerosondes have three jobs in MCTEX:

1. Extension of the upper-air network. Darwin (Fig. 2) has excellent rawinsonde and microwaveprofiler equipment, and it may be feasible to establish additional upper-air sites near the Cape Don lighthouse and at one or two places on the islands themselves. Gaps would nonetheless remain over the eastern parts of the islands, which have no practical access, and over the ocean to the north and west. Observations in these regions are vital to interpreting the impact of island convection on the scale of a climate model grid, and we plan to obtain such observations from aerosondes. The plan at present calls for four aircraft simulta-

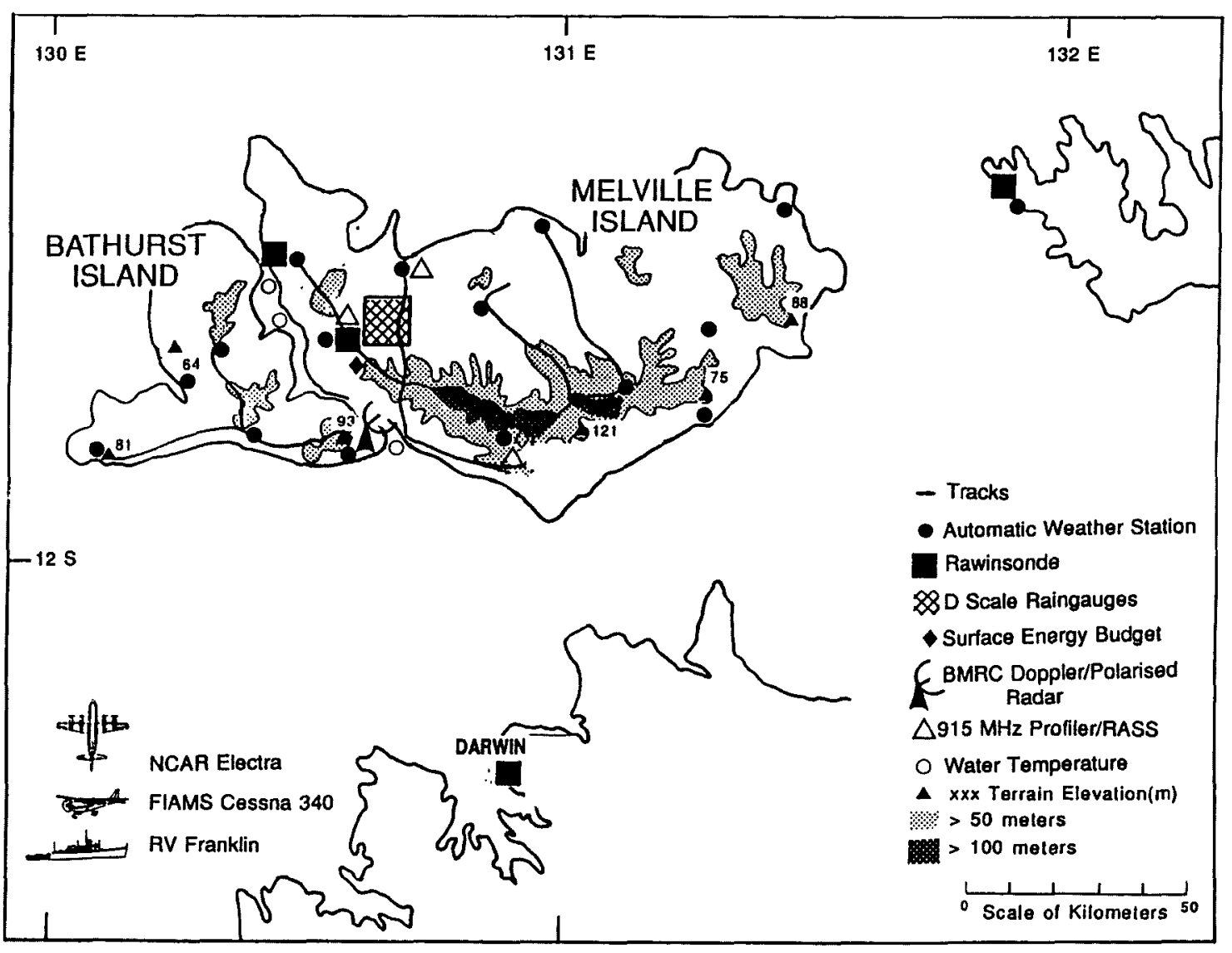

Fig. 2: Area of the Maritime Continent Thunderstorm Experiment, 1995-1996. 
neously, flying continuous sounding cycles between sea level and $\sim 5-\mathrm{km}$ altitude.

2. Sea-breeze monitoring. Import of warm moist air via the sea-breeze circulation is of great importance in the convection cycle (Simpson et al., 1993). Aerosondes provide the only practical means of monitoring the sea-breeze at low altitude throughout a 24-hour period.

3. Boundary-layer measurement. A surface flux monitoring station may be maintained during the experiment, and it will be of interest to determine whether its measurements are representative of the islands as a group. The necessary data can be obtained by aerosondes flying low-level traverses. Flight planning will not be too complicated because the islands have low relief. The main constraint will be the convective complexes. They are sufficiently powerful to lift an aerosonde quickly up to the freezing level, at which point it might be ejected in a block of ice!

MCTEX will include manned aircraft and ships which, in the absence of aerosondes, would be assigned to these surveys; now we expect them to be freed for more specialized work. The aerosonde fleet meanwhile can provide coverage on a scale that otherwise would have been impracticably difficult and expensive.

\section{Boundary-Layer Measurements}

The Tropical Oceans Global Atmosphere (TOGA) program, and particularly TOGA COARE, has emphasized that the oceanic regime is intimately coupled to processes occurring in the atmospheric boundary layer and to fresh water incursion from rainfall. Almost all open-ocean data at this interface are now obtained from drifting and moored buoys. These buoys measure oceanic structure in detail via thermistor chains, current meters, and the like, but their atmospheric observations are confined to the surface. An aerosonde can provide the missing information on atmospheric structure, including highresolution profiles of temperature, moisture, and wind (Fig. 3). GPS-based calculations, for example, could determine wind components with accuracies better than $1 \mathrm{~m} / \mathrm{s}$ on horizontal scales $<100 \mathrm{~m}$. Meanwhile other aerosondes equipped with rain gauges and radiation sensors could complete the full data set needed for flux budget calculations between the atmosphere and ocean. Further details of oceanic conditions and clouds might be observed by aircraft carrying video equipment.

Aerosondes could operate likewise in conjunction with a ship, and so offer the horizontal freedom lacking with ship-launched rawinsondes and tethered balloons. The ship could, for example, direct aircraft to observe an approaching squall line. This leads naturally to the question of whether aerosondes could be based aboard ship. Unfortunately, although launch should not be difficult, recovery (by net) has proven unreliable in military experience. Given the flexibility afforded by the aerosonde's long range, it may be more economical and convenient to recover on land. Control of the aircraft could be passed between ship and shore as appropriate during the mission.

\section{Wildlife Monitoring}

Monitoring of marine wildlife, and particularly of marine mammals, is a matter of substantial public concern and scientific interest. In the United States any activities that might affect the welfare of such animals are regulated by the Marine Mammal Protection Act, the Endangered Species Act, and the Environmental Protection Act. Better monitoring is essential if regulation is to have a sound scientific basis and be neither too lax nor too restrictive. Furthermore, apart from the regulatory pressures, marine mammals are of intrinsic scientific interest and offer a powerful means for assessing the ocean at large. They have particular habitat and dietary preferences, so their distribution and behavior are indicators for many physical and biological processes in the ocean.

Aircraft are indispensible monitoring platforms, offering speed, flexibility, and high viewing angle (e.g., Bayliss, 1986). However, even small manned aircraft are costly and cannot operate over long distances; large aircraft are prohibitively expensive except for specialized applications. A further problem is that animals react to aircraft, and the need for close observation thus conflicts with the need to minimize reaction to the observational platform. This affects not only studies of "natural" behavior, but also programs designed to test responses to artificial stimuli under experimental control.

These drawbacks can be addressed by an aerosonde equipped with a video camera. By comparison with manned aircraft it not only offers a more useful combination of range and economy, but it is also substantially less noisy and less visible. Against these advantages there is the point that a camera cannot be as effective as a human observer with a wide field of view, but it has been demonstrated that video is sufficient for identification and behavioral analysis (Watkins and Shevill, 1982). We are designing a short-range trial near a coastal station, using a camera and transmitter weighing $<1$ $\mathrm{kg}$. One can imagine much more ambitious missions, since with this payload even our initial trials aerosonde (Table 2 ) could fly $\sim 2,500 \mathrm{~km}$ and stay up for more than a day. However when dealing with video data, be it for wildlife monitoring or ice reconnaissance, or perhaps even debris detection to indicate an oceanic front, there comes inevitably a formidable data deluge. The data rate for real-time video would be much too high for relay via satellite, because an aerosonde could not carry the necessary high-gain transmitter. Onboard recording also would not be possible for extended periods unless some care were exercised in data compression. Moreover a human being could hardly be expected to watch 
all of the footage, either in real time or after the fact. Long video-survey missions therefore will be practical only when combined with automated techniques for recognizing features of interest.

\section{Data Relay}

Although for long-range operations an aerosonde will rely on satellites for communication, there may be circumstances in which the aircraft itself would be useful as a relay platform. The application might arise, for example, if a ship had high-volume data to send to a base beyond direct line of sight. The economics of an aerosonde versus satellite relay would depend upon the required data rate and associated transponder cost. In any case the aerosonde could in principle offer a high rate (even video) line-of-sight relay between surface stations separated by $2 \sqrt{ } 2 \mathrm{hR}_{\text {earth }}$, $\mathrm{h}$ being the altitude of the aircraft. This works out to $\sim 400 \mathrm{~km}$ from $3-\mathrm{km}$ altitude.

\section{Development Program}

The aerosonde program, which began in 1992 as a collaborative effort between The Insitu Group and the Australian Bureau of Meteorology, has now reached a threshold. Three systems-testbed aircraft have been built, and the components necessary for practical long-range operations have been tested. It is now time to proceed with a program of field trials with increasingly ambitious objectives. We hope that these will include mammal monitoring, tropical cyclone reconnaissance, and MCTEX in 1995, and participation in several further field experiments over the next 2 years.

The pace of development will depend on funding. Potential users in meteorology are working energetically to push the program forward, particularly through proposals for field trials at an early stage. We hope that oceanographers will become similarly involved, and that the development program thereby will include a propitious mix of oceanographic and meteorological applications.

\section{Acknowledgments}

Many thanks to Steve Lord of the U.S. National Meteorological Center for his observations on the relationship between small aircraft and small computers. Many thanks also to Kurt Fristrup of Woods Hole Oceanographic Institution for his proposal to use aerosondes in marine mammal monitoring. Aerosonde development is maintained in part by gratefully received funding from the U.S. Office of Naval Research under grant N-0014-89-J1737.

\section{References}

Albritton, D.L., F.C. Fehsenfeld, and A.F. Tuck, 1990: Instrumental requirements for global atmospheric chemistry. Science, 250, 75-81.

P. Bayliss, 1986: Factors affecting aerial surveys of marine fauna, and their relationship to a census of dugongs in the coastal waters of the Northern Territory. Australian Wildlife Research, 13: 27-37.

Goo, A.M.S., N. Arntz, and R.D. Murphy, 1989: Condor for high altitudes. Aerospace America, 27, 26.

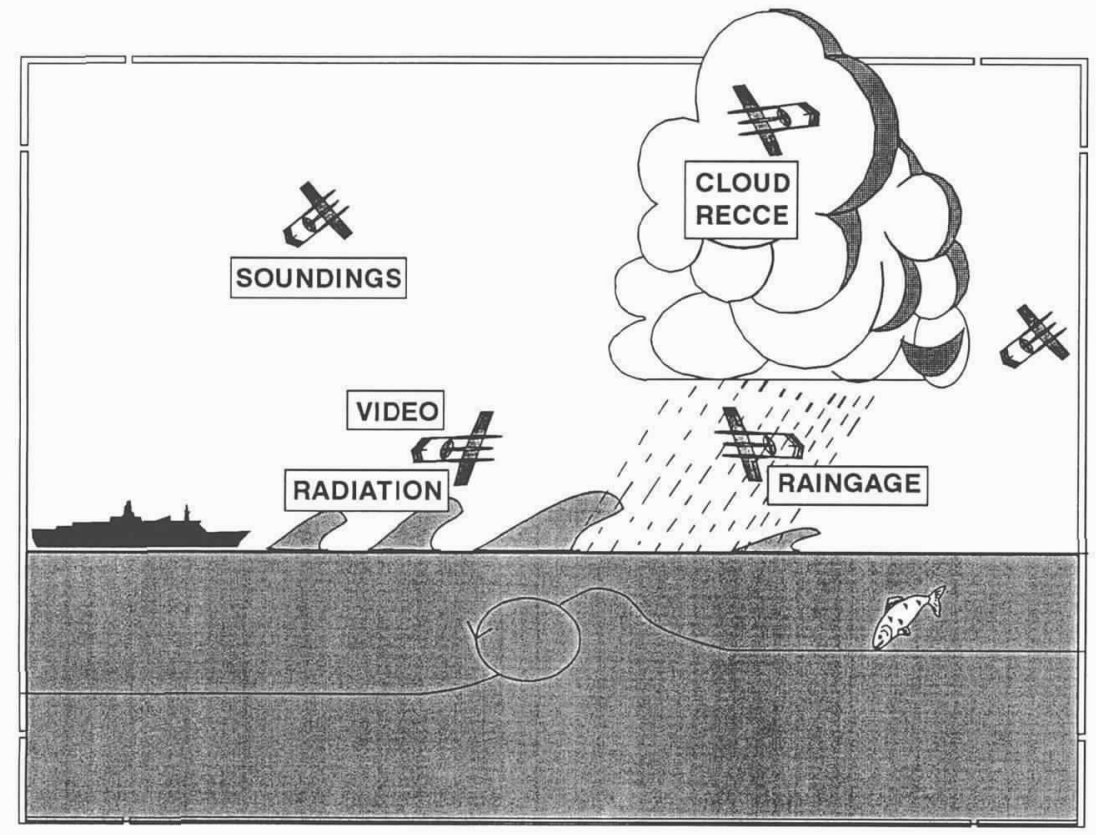

Fig. 3: Several aerosondes fying in conjunction could obtain the full set of data needed for flux budget calculations: boundary-layer structure, precipitation, broadband radiation, and ocean-surface and cloud conditions.

Holland, G.J., T. McGeer, and H. Youngren, 1992: Autonomous aerosondes for economical atmospheric soundings anywhere on the globe. Bull. Am. Meteorol. Soc., 73, 1987-1998.

Report of the ICSU/WMO Symposium on Tropical Cyclone Disasters. International Council of Scientific Unions, Beijing, October 1992.

Report to the IDNDR Scientific and Technical Committee on ICSU's Demonstration Project No. 3: Tropical Storms. International Council of Scientific Unions, New Delhi, February 1993.

Keenan, T.D., G.J. Holland, and M.J. Manton, 1989: TRMM ground truth in a monosonal environment: Darwin, Australia. Australian Meteorological Magazine, 36, 81-90.

Keenan, T.D., B.R. Morton, M.J. Manton, and G.J. Holland, 1989: The Island Thunderstorm Experiment (ITEX) — a study of tropical thunderstorms in the Maritime Continent. Bull. Am. Meteorol. Soc., 70, 152-159.

Langford, J.S. and K.A. Emanuel, 1990: An unmanned aircraft for dropwindsonde deployment and hurricane reconnaissance. Bull. Am. Meteorol. Soc., 74, 367-375.

McCormick, B.W., 1979: Aerodynamics, Aeronautics, and Flight Mechanics, Wiley, New York, 440 pp.

McGeer, T., 1991: Autonomous Aerosondes for Meteorological Measurements in Remote Areas. Technical Report, Aurora Flight Sciences, Alexandria, Virginia, USA.

Maritime Continent Thunderstorm Experiment. Bureau of Meteorology Research Centre, Melbourne, Australia, 1992.

Nilsson, J., 1992: Time-augmented GPS aviation and airport applications in Sweden. GPS World, 3, 38-42.

American Institute for Aeronautics and Astronautics. Proceedings of the 14th International Satellite Communications Conference, Washington, D.C., March 1992.

Simpson, J., T.D. Keenan, B. Ferrier, R.H. Simpson, and G.J. Holland, 1993: Cumulus mergers in the Maritime Continent region. Meteorol. Atmosph. Phys, 51, 73-99.

Ware, R., 1992: GPS soundings of the Earth's atmosphere. GPS World, 3.

Watkins, W.A. and W.E. Schevill, 1982: Observations of right whales. Fish. Bull., 80, 875-880. $\square$ 